\title{
Motivational factors for blood donation, potential barriers, and knowledge about blood donation in first-time and repeat blood donors
}

\author{
Shamsudeen Mohammed ${ }^{1 *}$ (D) and Harry Barton Essel ${ }^{2}$
}

\begin{abstract}
Background: Blood transfusion is an essential component of the health care system of every country and patients who require blood transfusion service as part of the clinical management of their condition have the right to expect that sufficient and safe blood will be available to meet their needs. However, this is not always the case, especially in developing countries. To recruit and retain adequate regular voluntary non-remunerated blood donors the motivators and barriers of donors must be understood. Equally important to this goal is the knowledge of blood donors.

Methodology: A cross-sectional study was conducted at the donor clinic of Tamale Teaching Hospital in the Northern Region of Ghana from 06 January to 02 February 2018. Purposive sampling technique was used to sample 355 eligible first-time and repeat whole blood donors. Data were collected face-to-face with a 27-item self-administered questionnaire. Chi-square test was used to determine the association between donor status and the motivators of blood donation, barriers to blood donation and the socio-demographic characteristics of donors.

Results: Out of the 350 donors, 192(54.9\%) were first-time blood donors while 158 (45.1\%) were repeat donors. Nearly all the donors, 316(90.3\%), indicated they were motivated to donate when someone they know is in need of blood. Over four-fifths of the donors endorsed good attitude of staff $(n=291,83.4 \%)$ and the desire to help other people in need of blood ( $n=298,85.1 \%$ ) as motivators. Approximately two-thirds, 223(63.7\%), of the donors endorsed poor attitude of staff as a deterrent to blood donation. More than half of the donors considered the level of privacy provided during pre-donation screening $(n=191,54.6 \%)$ and the concern that donated blood may be sold 178(50.9\%) as deterrents. Only a little over one-third of the donors knew the minimum age for blood donation $(n=126,36.0 \%)$ and the maximum number of donations per year $(n=132,37.7 \%)$.
\end{abstract}

Conclusion: Our findings suggest that public education on blood donation, regular prompts of donors to donate when there is a shortage, and friendly attitude of staff have the potential to motivate donors and eliminate barriers to blood donation.

Keywords: Blood donors, Blood donation, Motivators, Barriers, Knowledge, Repeat donors, First-time donors, Tamale teaching hospital, Ghana

\footnotetext{
* Correspondence: deen0233@gmail.com

${ }^{1}$ Department of Nursing, College of Nursing and Midwifery, Post office box

10, Nalerigu, Ghana

Full list of author information is available at the end of the article
}

(c) The Author(s). 2018 Open Access This article is distributed under the terms of the Creative Commons Attribution 4.0 International License (http://creativecommons.org/licenses/by/4.0/), which permits unrestricted use, distribution, and reproduction in any medium, provided you give appropriate credit to the original author(s) and the source, provide a link to the Creative Commons license, and indicate if changes were made. The Creative Commons Public Domain Dedication waiver (http://creativecommons.org/publicdomain/zero/1.0/) applies to the data made available in this article, unless otherwise stated. 


\section{Background}

Blood transfusion is an essential component of the healthcare system of every country and patients who require blood transfusion service as part of the clinical management of their condition have the right to expect that sufficient and safe blood will be available to meet their needs. However, this is not always the case, especially in developing countries. In many developing countries, there is a widespread shortfall between blood requirements and blood supplies and as a result, many patients die or suffer unnecessarily because they do not have access to blood and blood products [1]. The most affected are women and children. Blood transfusion in developing countries is often used to manage children with severe anaemia and women with pregnancy-related bleeding [2]. In 2017 about $65 \%$ of blood transfusions in low-income countries were for children under the age of 5 years [3]. In Ghana, more than $75 \%$ of donor blood in rural areas and $50 \%$ in urban areas are transfused to children under 5 years and women of childbearing age [4].

The high maternal and child mortality rates attributed to pregnancy related-complications, severe malaria, and anaemia, are evidence of the magnitude of the unmet need for blood transfusion in Africa [2]. About 34\% of maternal deaths in Africa are still attributed to severe bleeding during and after childbirth [5]. Furthermore, man-made natural disasters, road traffic accidents, and armed conflicts further increase the demand for blood transfusion in Africa. Regrettably, many countries in the region collect less than half of the blood needed to meet the transfusion requirements of their populations and predictably, access to blood remains a challenge in many African countries including Ghana $[2,6]$. Of the estimated 250, 000 units of blood required annually to meet the blood transfusion demand of patients in Ghana, 160, 624 units were collected in 2016. The majority of the donors were family replacement donors. Only $36.2 \%$ of the donors were voluntary non-remunerated blood donors [7, 8].

According to the World Health Organisation (WHO), voluntary non-remunerated blood donation is the surest approach to ensure sufficient supply of safe blood to meet national requirement of blood transfusion. However, only 62 countries have blood supplies based on close to $100 \%$ voluntary non-remunerated blood donations [9]. Blood donation systems in most countries largely depend on family replacement donors who donate blood to help a friend or family member in need of blood transfusion. These systems are rarely able to meet clinical demands for blood [1]. Nonetheless, family and/or replacement donors continue to dominate in sub-Saharan Africa generally because some society's belief blood is a precious sacred substance common to family and should be preserved in the family and not donated to strangers. As a result, blood is only donated to save the life and relieve the suffering of a hospitalised relative. Additionally, people who believe behavioural traits can be transferred through blood prefer to receive blood from a known person or family member. Moreover, replacement donation is less costly compared with blood from a volunteer donor [10-12].

For a hospital to recruit and retain adequate regular voluntary non-remunerated blood donors the motivators and deterrents of the donors must be understood. However, a literature search revealed inadequate studies in the area, particularly in Ghana. Out of 35 studies reviewed by Asamoah-akuok et al. [11], only three focused on motivators and deterrents of blood donors. Equally important to the goal of recruiting adequate voluntary donors is the knowledge of blood donors. Information about blood donation process demystifies myths and fears related to blood donation. People are motivated to donate when they are well informed about the process and the life-saving benefits of given blood [1]. Asamoah-akuok et al. found that the main deterrent to blood donation in sub-Saharan Africa is fear due to lack of knowledge and discouraging cultural and religious beliefs about blood donation [11]. It is against this backdrop that this study assessed first-time and repeat blood donors' motivators, barriers to donation, and knowledge about blood donation at the Tamale Teaching Hospital to understand the factors that motivate or discourage blood donation and to suggest cogent interventions to increase recruitment and retention of an adequate number of voluntary nonremunerated donors.

\section{Methods}

Study design, study site, and study population

A cross-sectional study was conducted at the blood donation centre (donor clinic) of Tamale Teaching Hospital (TTH) in the Northern Region of Ghana. The hospital serves patients largely from the Upper East, Upper West, and Northern Regions of Ghana. It is the only tertiary health facility in the three regions and serves as the teaching hospital for the medical school of University for Development Studies, Tamale campus. The hospital function in three important areas 1) medical education and training of physicians and other health professionals 2) provision of high-quality clinical care including specialised services and 3) undertake research into health issues for improving health care. All persons who donated blood at the donor clinic of the hospital from 06 January to 02 February 2018 constituted the population for the study. Blood donors were enlisted if they were above 18 years, irrespective of gender, and willing to participate in the survey. Non-donors at the clinic and donors who were unwilling to give consent were excluded. 


\section{Sampling technique and sample size}

Purposive sampling technique was used to recruit three hundred and fifty eligible first-time (persons donating for the first time) and repeat (donors who have donated two or more times) whole blood donors at the donor clinic of Tamale Teaching Hospital. Single population proportion formula was used to determine the sample size of 355 based on 36\% prevalence of knowledge about blood donation [13], 95\% confidence interval, and 5\% degree of error. Donors were assessed for eligibility, informed about the purpose of the study, and invited to participate in the study after a routine pre-donation screening. The study protocol was reviewed and approved by the institutional research and development committee of Tamale Teaching Hospital. Participation was voluntary and participants indicated consent by signing a consent form after adequate information was provided on the purpose of the study, its possible benefits, and their role in the study. Additionally, participants were informed they could withdraw from the study at any time. Sufficient time was allowed for participants to decide whether to participate in the study. We ensured confidentiality of the study data and maintained the anonymity of the study participants.

\section{Data collection tool}

Data were collected face-to-face with a 27-item self-administered questionnaire. It was designed after a comprehensive literature review to include relevant variables from previously published studies [11, 14-18]. The questionnaire assessed the following four categories: Socio-demographic characteristics of participants (7 items), motivators of blood donation (6 items), barriers to blood donation (9 items), and knowledge about blood donation (5 items). Table 1 presents the variables that were collected in each category. The knowledge questions were constructed based on information from the National Blood Donation service of Ghana. Two professionals in the area of blood donation reviewed the questionnaire and deemed it content valid. Recommended amendments after the review were made to improve the instrument. We pretested the questionnaire on 15 outpatient to ascertain the clarity and practicability of the questionnaire and to identify poorly constructed items. Relevant changes were made after the pre-test. Two final year nursing students, who were trained on how to administer and record responses, administered the questionnaire to the donors. The principal investigator supervised the data collection.

\section{Data management and analysis}

Collected data were checked for completeness, cleaned, coded, and entered into Microsoft Excel spreadsheet before exported into Stata v14 for analysis. Five [5] questionnaires were disqualified for incompleteness.
Table 1 Variables collected in each category of the questionnaire

\begin{tabular}{|c|c|}
\hline Category & Variables collected \\
\hline $\begin{array}{l}\text { 1. Participants socio- } \\
\text { demographic characteristics }\end{array}$ & $\begin{array}{l}\text { Age, sex, marital status, religion, education, } \\
\text { employment, donor status }\end{array}$ \\
\hline $\begin{array}{l}\text { 2. Motivators of blood } \\
\text { donation }\end{array}$ & $\begin{array}{l}\text { when someone I know is in need, good } \\
\text { attitude staff, incentives, appeals on radio, } \\
\text { television, or from a famous person, a } \\
\text { reminder to donate when there is a } \\
\text { shortage, and to help a person in need }\end{array}$ \\
\hline $\begin{array}{l}\text { 3. Potential barriers to } \\
\text { blood donation }\end{array}$ & $\begin{array}{l}\text { Poor attitude of staff, level of privacy } \\
\text { during screening, fear of weakness, fear of } \\
\text { needles/pain, fear of contagion, fear of } \\
\text { feeling faint or dizzy, the inconvenience of } \\
\text { donors' clinic, donated blood may be sold, } \\
\text { and absence of incentives }\end{array}$ \\
\hline $\begin{array}{l}\text { 4. Knowledge of blood } \\
\text { donation }\end{array}$ & $\begin{array}{l}\text { Minimum age for blood donation, } \\
\text { maximum number of donations in a year, } \\
\text { interval between two blood donations, } \\
\text { does donated blood expire, and is a } \\
\text { person positive for HIV/AIDS eligible to } \\
\text { donate blood }\end{array}$ \\
\hline
\end{tabular}

We analysed 350 completed questionnaires. For descriptive statistics, frequency, percentage, mean, and standard deviation (SD) were computed. Using donor status (first- time and repeat) as a categorical dependent variable, the association of donor status and socio-demographic characteristics, motivators of blood donation, and barriers to blood donation was determined using Pearson's chisquare. For independent variables that were small (expected values less than 5) Fisher's exact test was used to determine the association. For the Pearson's chi-square and Fisher's exact tests, proportions, percentages, chi-values, and $P$ values were presented in tables. The significance level was set at 0.05 .

\section{Results}

\section{Background characteristics}

Out of the 355 questionnaires that were administered, five [5] questionnaires were disqualified for incompleteness. We analysed a total of 350 completed questionnaires. Participants' background characteristics are presented in Table 2. Out of the 350 donors, 192(54.9\%) were first-time blood donors. The remaining 158 (45.1\%) were repeat donors. The majority, 246 (70.3\%), of the donors were in the age range of $20-35$ years. Only $11(3.1 \%)$ donors were older than 50 years. Mean age of donors in this study was 29.2(SD $=9.1)$ years. Most, $246(73.1 \%)$, of the donors were males. Only $94(26.9 \%)$ were females. Among the participants, $142(40.6 \%)$ were never married while 182 $(52.0 \%)$ were married at the time of the survey. Of the 350 participants, 233(66.8\%) were Muslims and 82(23.4\%), $100(28.6 \%)$, and $96(27.4 \%)$ had primary, secondary, and tertiary level education, respectively. Approximately one-fifth, $72(20.6 \%)$, of the participants had no formal education. The participants were mainly formal sector 
Table 2 Background characteristics of participants

\begin{tabular}{|c|c|c|}
\hline Characteristics & Number & Percent \\
\hline \multicolumn{3}{|l|}{ Age (years) } \\
\hline$<20$ & 31 & 8.86 \\
\hline $20-35$ & 246 & 70.29 \\
\hline $36-50$ & 62 & 17.71 \\
\hline$>50$ & 11 & 3.14 \\
\hline Mean (SD) & $29.22(9.11)$ & \\
\hline \multicolumn{3}{|l|}{ Sex } \\
\hline Male & 246 & 73.14 \\
\hline Female & 94 & 26.86 \\
\hline \multicolumn{3}{|l|}{ Marital status } \\
\hline Never married & 142 & 40.57 \\
\hline Married & 182 & 52.00 \\
\hline Divorced/separated/widowed & 26 & 7.43 \\
\hline \multicolumn{3}{|l|}{ Religion } \\
\hline Christianity & 116 & 33.24 \\
\hline Islam & 233 & 66.76 \\
\hline \multicolumn{3}{|l|}{ Education } \\
\hline No formal education & 72 & 20.57 \\
\hline Primary & 82 & 23.43 \\
\hline Secondary & 100 & 28.57 \\
\hline Tertiary & 96 & 27.43 \\
\hline \multicolumn{3}{|l|}{ Employment status } \\
\hline Formal sector employment & 132 & 37.71 \\
\hline Self-employed & 125 & 35.71 \\
\hline Unemployed & 31 & 8.86 \\
\hline Student & 62 & 17.71 \\
\hline \multicolumn{3}{|l|}{ Donor status } \\
\hline First time & 192 & 54.86 \\
\hline Repeat & 158 & 45.14 \\
\hline
\end{tabular}

employees $(n=132,37.7 \%)$ and self-employed $(n=125$, $35.7 \%)$ with $62(17.7 \%)$ being students at the time of the study.

\section{Donor status and background characteristics}

The association between donor status and background characteristics of the participants is presented in Table 3. Of the donors in the age range of $20-35$ years, $137(55.7 \%)$ were first-time donors and 109(44.3\%) were repeat donors. Nearly two-thirds, 7(63.6\%), of donors older than 50 years were repeat donors while the remaining $4(36.4 \%)$ were first-time donors. Male donors constituted the highest number of first-time donors $(n=121,63.0 \%)$, and repeat donors $(n=135,85.4 \%)$. Of the $94(26.9 \%)$ females in this study, 71(36.9\%) were first-time donors while $23(14.6 \%)$ were repeat donors. Further, the chi-square test in Table 3 shows a significant association $\left(\mathrm{x}^{2}=11.2740, p=0.004\right)$ between donor status and marital status. Almost twothirds, 88(61.9\%), of the participants who were never married were first-time donors whereas married participants accounted for the highest number $(n=97,53.3 \%)$ of repeat donors. Most, 61(63.5\%), of the donors with tertiary level education were first-time donors. Participants with no formal education were largely $(n=40,55.6 \%)$ repeat donors. The majority of formal sector employees were repeat donors. Nearly three-fourths of donors who were unemployed $(n=22,70.9 \%)$ and students $(n=45,72.6 \%)$ were first-time donors. The results demonstrate a significant association $\left(x^{2}=15.4324, p=0.001\right)$ between donor status and employment status of participants in this study.

\section{Motivators of blood donation}

Table 4 presents a descriptive summary of the six motivators of blood donation participants responded to in this study. Nearly all the donors, 316(90.3\%), indicated they were motivated to donate when someone they know is in need of blood. Over four-fifths of the donors endorsed good attitude of staff $(n=291,83.4 \%)$ and the desire to help other people in need of blood $(n=298$, $85.1 \%$ ) as motivators. The offer of compensation (incentives) for blood donation was the least, 187(53.4\%), motivator reported. Two hundred and forty-three $(69.4 \%)$ and 263(75.1\%) donors endorsed appeals on radio, television or from a famous person and reminder to donate when there is a shortage of blood as motivators, respectively.

\section{Motivators of blood donation in first-time and repeat donors}

Analysis of the association between donor status and motivational factors is presented in Table 5. One hundred and seventy-one $(89.1 \%)$ of the donors who were motivated to donate when someone they know is in need were first-time donors and 145(91.8\%) were repeat donors. The attitude of staff was important to the majority of both first-time donors $(n=161,83.9 \%)$ and repeat donors $(n$ $=130,82.8 \%$ ). Further, the desire to help a person in need of blood as a motivator was significantly associated $(\times 2=5.0953, p=0.024)$ with donor status as approximately four-fifths of first-time donors $(n=156$, $81.3 \%)$ and repeat donors $(n=142,89.9 \%)$ endorsed this motivator. A statistically significant $\left(\mathrm{x}^{2}=14.0660, p=<\right.$ 0.001 ) number of the donors who endorsed incentives as a motivator were first-time donors $(n=120,62.5 \%)$. Only $67(42.4 \%)$ of them were repeat donors. Slightly over three-fourths, $122(77.2 \%)$, of the participants who considered a reminder to donate when there is a shortage of blood as a motivator were repeat donors. Of the donors that endorsed appeals on radio, television or from a famous person as a motivator, 133(69.3\%) were first-time donors while $110(69.6 \%)$ of them were repeat donors. 
Table 3 Association of donor status and socio-demographic characteristics

\begin{tabular}{|c|c|c|c|c|}
\hline \multirow[t]{2}{*}{ Characteristics } & \multicolumn{2}{|c|}{ Donor Status } & \multirow[t]{2}{*}{$x^{2}$} & \multirow[t]{2}{*}{$P$ value } \\
\hline & First time & Repeat & & \\
\hline \multicolumn{5}{|l|}{ Age (years) } \\
\hline$<20$ & $22(70.97)$ & $9(29.03)$ & \multirow{4}{*}{6.4731} & \multirow{4}{*}{$0.092^{\mathrm{a}}$} \\
\hline $20-35$ & 137(55.69) & 109(44.31) & & \\
\hline $36-50$ & $29(46.77)$ & $33(53.23)$ & & \\
\hline$>50$ & $4(36.36)$ & $7(63.64)$ & & \\
\hline \multicolumn{5}{|l|}{ Sex } \\
\hline Male & $121(63.02)$ & 135(85.44) & \multirow[t]{2}{*}{22.1827} & \multirow[t]{2}{*}{$<0.001$} \\
\hline Female & $71(36.98)$ & $23(14.56)$ & & \\
\hline \multicolumn{5}{|l|}{ Marital status } \\
\hline Never married & $88(61.97)$ & $54(38.03)$ & \multirow{3}{*}{11.2740} & \multirow{3}{*}{0.004} \\
\hline Married & $85(46.70)$ & $97(53.30)$ & & \\
\hline Divorce/separated/widowed & 19(73.08) & $7(26.92)$ & & \\
\hline \multicolumn{5}{|l|}{ Religion } \\
\hline Christianity & $72(62.07)$ & $44(37.93)$ & \multirow[t]{2}{*}{3.7794} & \multirow[t]{2}{*}{0.052} \\
\hline Islam & $119(51.07)$ & $114(48.93)$ & & \\
\hline \multicolumn{5}{|l|}{ Education } \\
\hline No formal education & $32(44.44)$ & $40(55.56)$ & & \\
\hline Primary & $50(60.98)$ & $32(39.02)$ & \multirow[t]{3}{*}{8.7010} & \multirow[t]{3}{*}{0.034} \\
\hline Secondary & $49(49.00)$ & $51(51.00)$ & & \\
\hline Tertiary & $61(63.54)$ & $35(36.46)$ & & \\
\hline \multicolumn{5}{|l|}{ Employment status } \\
\hline Formal sector employment & $62(46.97)$ & $70(53.03)$ & & \\
\hline Self-employed & $63(50.40)$ & $62(49.60)$ & \multirow[t]{3}{*}{15.4324} & \multirow[t]{3}{*}{0.001} \\
\hline Unemployed & $22(70.97)$ & $9(29.03)$ & & \\
\hline Student & $45(72.58)$ & $17(27.42)$ & & \\
\hline
\end{tabular}

${ }^{a}$ Fisher's exact test

\section{Barriers to blood donation}

The barriers of first-time and repeat donors were evaluated with nine barriers to blood donation and presented in Table 6. Approximately two-thirds, 223(63.7\%), of the donors endorsed poor attitude of staff as a barrier to blood donation. More than half of the donors considered

Table 4 Motivators of blood donation

\begin{tabular}{ll}
\hline Motivator variables & Number (\%) \\
\hline When someone I know is in need & $316(90.29)$ \\
Good attitude of staff & $291(83.38)$ \\
Incentives for donation & $187(53.43)$ \\
Appeals on radio, television, or from a famous person & $243(69.43)$ \\
Reminder to donate when there is a shortage & $263(75.14)$ \\
To help a person in need & 298(85.14) \\
\hline
\end{tabular}

the level of privacy provided during pre-donation screening ( $n=191,54.6 \%)$ and the concern that donated blood may be sold $(n=178,50.9 \%)$ as barriers. Only one-third of the donors endorsed fear of weakness after donation $(n=125,35.7 \%)$, fear of needles/pain $(n=119$, $34.1 \%)$, and inconvenience of donors clinic $(n=127$, $36.3 \%$ ) as barriers. Further, only $39.7 \%$ and $38.6 \%$ of the donors recognised fear of contagion and absence of a gift or reward as barriers to blood donation, respectively.

Barriers to blood donation in first-time and repeat donors Result of the association of donor status and deterrents to blood donation is presented in Table 7. Poor attitude of staff at the donors' clinic was a major barrier among first-time donors 120(62.5\%) and repeat donors 103(65.2\%). Privacy during pre-donation screening was an important barrier for more than half of both first-time donors $109(56.8 \%)$ and repeat donors $82(51.9 \%)$. Of the number 
Table 5 Association of donor status and motivators of blood donation

\begin{tabular}{|c|c|c|c|c|}
\hline \multirow[t]{2}{*}{ Motivator variables } & \multicolumn{2}{|c|}{ Donation Status } & \multirow[t]{2}{*}{$x^{2}$} & \multirow[t]{2}{*}{$P$ value } \\
\hline & First-time & Repeat & & \\
\hline \multicolumn{5}{|c|}{ When someone I know is in need } \\
\hline Yes & $171(89.06)$ & 145(91.77) & 0.7256 & 0.394 \\
\hline No & 21(10.94) & 13(8.23) & & \\
\hline \multicolumn{5}{|l|}{ Good attitude of staff } \\
\hline Yes & $161(83.85)$ & $130(82.80)$ & 0.0689 & 0.793 \\
\hline No & $31(16.15)$ & $27(17.20)$ & & \\
\hline \multicolumn{5}{|c|}{ Incentives for donation } \\
\hline Yes & $120(62.50)$ & $67(42.41)$ & 14.0660 & $<0.001$ \\
\hline No & $72(37.50)$ & $91(57.59)$ & & \\
\hline \multicolumn{5}{|c|}{ Appeals on radio, television, or from a famous person } \\
\hline Yes & 133(69.27) & $110(69.62)$ & 0.0050 & 0.944 \\
\hline No & $59(30.73)$ & 48(30.38) & & \\
\hline \multicolumn{5}{|c|}{ Reminder to donate when there is a shortage } \\
\hline Yes & $141(73.44)$ & $122(77.22)$ & 0.6622 & 0.416 \\
\hline No & $51(26.56)$ & $36(22.78)$ & & \\
\hline \multicolumn{5}{|c|}{ To help a person in need } \\
\hline Yes & $156(81.25)$ & 142(89.87) & 5.0953 & 0.024 \\
\hline No & $36(18.75)$ & 16(10.13) & & \\
\hline
\end{tabular}

that was deterred by the concern that donated may be sold, $112(58.3 \%)$ were first-time donors while $66(41.8 \%)$ were repeat donors. As illustrated in Table 7 , more of repeat donors than first-time donors indicated they were not deterred by weakness after donation $(74.1$ vs $56.3 \% p=$ 0.001 ), fear of needles/pain (76.6 vs $57.1 \%, p=<0.001$ ), or inconvenience of donors clinic $(72.2$ vs $56.8 \%, p=$ $0.003)$. The results also show that only $86(44.8 \%)$ of first-time donors and 53(33.5\%) of repeat donors considered fear of contagion as a barrier to blood donation $\left(\mathrm{x}^{2}=4.5796, p=0.032\right)$. Most of the donors, $109(57.4 \%)$ of first-time donors and 103(66.5\%) of repeat donors,

Table 6 Barriers to blood donation

\begin{tabular}{ll}
\hline Barriers & Number (\%) \\
\hline Poor attitude of staff & $223(63.71)$ \\
Level of privacy during screening & $191(54.57)$ \\
Fear of weakness after donation & $125(35.71)$ \\
Fear of needles or pain & $119(34.10)$ \\
Fear of contagion & $139(39.71)$ \\
Fear of feeling faint or dizzy & $138(39.43)$ \\
Inconvenience of donors' clinic & $127(36.29)$ \\
Donated blood may be sold & $178(50.86)$ \\
Absence of a gift or reward & $133(38.55)$ \\
\hline
\end{tabular}

Table 7 Association of donor status and barriers to blood donation

\begin{tabular}{|c|c|c|c|c|}
\hline \multirow[t]{2}{*}{ Barriers } & \multicolumn{2}{|c|}{ Donor Status } & \multirow[t]{2}{*}{$x^{2}$} & \multirow[t]{2}{*}{$P$ value } \\
\hline & First-time & Repeat & & \\
\hline \multicolumn{5}{|c|}{ Poor attitude of staff } \\
\hline Yes & $120(62.50)$ & 103(65.19) & 0.2713 & 0.602 \\
\hline No & $72(37.50)$ & $55(34.81)$ & & \\
\hline
\end{tabular}

Level of privacy during screening

$\begin{array}{lllll}\text { Yes } & 109(56.77) & 82(51.90) & 0.8299 & 0.362 \\ \text { No } & 83(43.23) & 76(48.10) & & \end{array}$

Fear of weakness after donation

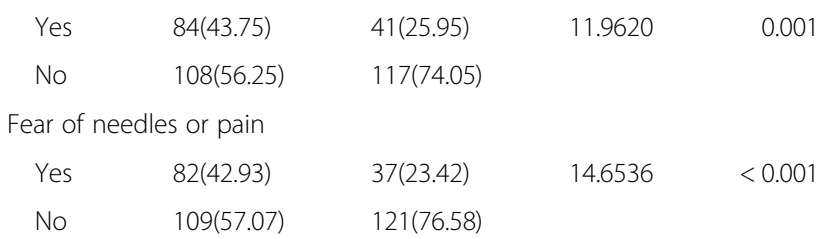

Fear of contagion

$\begin{array}{lllll}\text { Yes } & \text { 86(44.79) } & \text { 53(33.54) } & 4.5796 & 0.032 \\ \text { No } & 106(55.21) & 105(66.46) & & \end{array}$

Fear of feeling faint or dizzy

\begin{tabular}{|c|c|c|c|c|}
\hline Yes & $93(48.44)$ & $45(28.48)$ & 14.4537 & $<0.001$ \\
\hline No & $99(51.56)$ & 113(71.52) & & \\
\hline \multicolumn{5}{|c|}{ nconvenient of donor clinic } \\
\hline Yes & $83(43.23)$ & $44(27.85)$ & 8.8693 & 0.003 \\
\hline No & 109(56.77) & $114(72.15)$ & & \\
\hline \multicolumn{5}{|c|}{ Donated blood may be sold } \\
\hline Yes & 112(58.33) & $66(41.77)$ & 9.5118 & 0.002 \\
\hline No & $80(41.67)$ & $92(58.23)$ & & \\
\hline \multicolumn{5}{|c|}{ absence of a gift or reward } \\
\hline Yes & $81(42.63)$ & $52(33.55)$ & 2.9730 & 0.085 \\
\hline No & 109(57.37) & $103(66.45)$ & & \\
\hline
\end{tabular}

did not consider the absence of gift/reward (incentives) as a barrier to blood donation.

\section{Blood donor's knowledge of blood donation}

Table 8 summarize donors' knowledge about blood donation. Only a little over one-third of the donors knew the minimum age for blood donation $(n=126$, $36.0 \%)$ and the maximum number of donations per year $(n=132,37.7 \%)$. As illustrated in Table 8, 152(43.4\%) of the participants answered correctly that the interval between two donations is 4 month. Three-fourths, 264.(75.4\%), of the donors knew that donated blood expires. Almost all, 319(91.4\%), the participants answered correctly that a person positive for HIV/AIDS is not eligible to donate blood. 
Table 8 Blood donor's knowledge about blood donation

\begin{tabular}{lcc}
\hline Knowledge variables & Number & Percent \\
\hline Minimum age for blood donation & & \\
$<$ 17 years & 59 & 16.86 \\
17-18 years & 126 & 36.00 \\
$>$ 18 years & 165 & 47.14 \\
Maximum number of donations in a year & \\
Once & 81 & 23.14 \\
Twice & 93 & 26.57 \\
Thrice & 132 & 37.71 \\
Four or more times & 44 & 12.57 \\
Interval between two blood donations & \\
$<4$ months & 136 & 38.86 \\
4 months & 152 & 43.43 \\
5 or more months & 62 & 17.71 \\
Does donated blood expire & & \\
Yes & 264 & 75.43 \\
No & 86 & 24.57 \\
HIV/AIDS affected persons can donate blood & 30 & 8.60 \\
Yes & 319 & 91.40 \\
No & & \\
\hline
\end{tabular}

\section{Discussion}

To meet the blood transfusion demand and ensure adequate and constant supply of blood in all hospitals where blood transfusion is performed, it is essential to understand the motivators and barriers to blood donation for the formulation and effective implementation of donor recruitment programmes. In this hospital-based survey, we found that the donors were predominantly first-time donors, which contradicts findings reported in earlier studies $[14,19]$. The inconsistency may be due to the fact that the earlier studies were conducted in developed countries. One important implication of the finding is that the hospital may be unable to ensure adequate, constant, and safe blood supply since the majority of its donors are first-time donors who may not return to donate. Further, Allain argue that the risk of infection is high in first-time donors compared to repeat donors [20]. Hence, to ensure a safe and adequate blood supply, management of the donor clinic need to institute strategies to retain first-time donors as voluntary regular donors.

Evidence from a review in sub-Saharan Africa indicates that altruism is the most common motivator associated with the return of donors for more donations in the region [11]. For all donor groups in this study, the desire to help a family member or a friend in need of blood was the major motivator, which is inconsistent with studies in Germany [14], Saudi Arabia [16] and Senegal [21]. Altruistic donors, unlike those in this study, are influenced by the desire to help others and to improve the health of people they may never meet [1]. Contrary to this, the majority of donors in this study donated to meet the transfusion needs of hospitalised friends or family members and not to help others they do not know. However, it is important to note that some recipients prefer blood from a relative or family member because they belief characteristics of a donor can be transferred to the recipient through the blood. In Cameroon Koster and Hassall found that donating blood to a relative was considered much more acceptable compared with donating blood to an institution or a stranger who may be undeserving of the donor's family 'good' blood [12]. This may explain why donors in the current study donated blood primarily to save the life of either a family member or a friend.

Good attitude of staff at the donor clinic, a donors desire to help other people, and a reminder to donate when there is a shortage of blood were also endorsed as strong motivators for blood donation. Shaz et al. reported similar findings among African Americans in the United State [22]. Consistent with our finding, awareness of blood shortage was reported in Senegal as one of two main motivators of blood donation [21]. In addition, when Mauka and colleagues surveyed blood donors in Tanzania, they found that good previous donation experience was significantly associated with repeat donation [23]. This suggests that friendly attitude of staff and a good relationship between staff and donors may influence the return of donors to donate more. Similar to a previous study [24], the offer of incentives was the least endorsed motivator in this study which is in contrast to a study in South Africa [12]. In the South African study incentives in the form of gift items, time off work, money, recognition among others was the second most endorsed motivator [12]. The concept of incentives for donation may be less important in this study because the participants were predominantly first-time donors donating blood for either a family member or a friend.

The current study found that poor attitude of staff was the major reported barrier to blood donation among all the donor groups. However, more repeat donors than first-time donors endorsed the factor as a barrier. Likewise, Shaz et al. reported poor attitude of staff as a deterrent when they surveyed African Americans and white blood donors [22]. This finding explains why the good attitude of staff was endorsed as one of the major motivators in this study. Donors feel satisfied and motivated to return when they receive good care. This suggests that effective communication, counselling, and friendly attitude of staff have the potential to motivate donors and eliminate barriers to blood donation. The level of privacy provided during pre-donation screening and the concern that donated blood may be sold to patients in need of blood were also 
endorsed as strong barriers to blood donation. Similarly, Shaz et al. reported privacy during pre-donation screening as a factor that influences the decision to donate [22]. Regarding the concern that donated blood may be sold, a study in India reported similar concerns in $4.2 \%$ of college students, which is lower than what was found in this study [25]. Privacy during pre-donation screening and the concern that donated blood may be sold were more important to first-time donors compared to repeat donors in this study.

For all donor groups, fear of weakness, fear of needles/ pain, and fear of contagion were not recognised as important barriers to blood donation. Similarly, when Shaz et al. surveyed college age blood donors they found that pain, feeling of faint and dizziness were not important deterrents [15]. Likewise, Alfouzan reported fear of needles and pain in only $37.6 \%$ and $25.9 \%$ when he surveyed blood donors in Saudi Arabia, respectively [16]. However, Asamoah-akuoko and colleagues reported fears related to pain, adverse effects, and contagion as an important deterrent when they review studies on blood donation in sub-Saharan Africa [11].

The convenience of a blood donation centre, the times at which it open and waiting times can act as barriers to blood donation. Studies have shown that both first-time and repeat donors are motivated to donate when the process involves little or no disruption to their normal activities [1]. In this study, the inconvenience of donor clinic and absence of gift/reward were not considered important barriers to blood donation. Consistent with this finding, Yuan et al. reported unappealing incentives as the least rank deterrent among donors at a university campus in California. However, they reported inconvenient operating time and location of the donor centre among the top deterrents in their study, which is inconsistent with our finding [26]. Likewise, Schlumpf et al. reported the lack of a convenient place to donate as a major deterrent to blood donation [27]. Our finding may be attributed to the fixed location of the clinic, its nearness to the town centre, and the availability of reliable transport to the facility, as these factors are thought to ease inconvenience [1].

We found that more than half of the donors in the current study did not know the minimum age for blood donation, maximum number of donations in a year, and the recommended interval between two donations. The current results are consistent with the results of an earlier study in Saudi Arabia [16] but contradict those of Jemberu et al in Ethiopia [28]. These findings underscore the need for blood donation education campaigns in communities, on the radio, and television to educate the public about blood donation. However, almost all the donors in this study knew that persons positive for HIV/AIDS are not eligible to donate blood.

\section{Conclusion}

We found that donors desire to help a family member or a friend in need of blood was the most cited motivator for blood donation in this study followed by a positive attitude of staff at the donor clinic, the desire to help other people, and a reminder to donate when there is a shortage of blood. Poor attitude of staff was reported as the major barrier to blood donation followed by the level of privacy provided during pre-donation screening and the concern that donated blood may be sold to patients in need of blood. Our findings suggest that public education on blood donation, regular prompts of donors to donate when there is a shortage, and friendly attitude of staff have the potential to motivate donors and eliminate barriers to blood donation.

\section{Abbreviations}

HIV/AIDS: Human Immunodeficiency Virus/Acquired Immunodeficiency

Syndrome; TTH: Tamale Teaching Hospital; WHO: World Health Organisation

\section{Acknowledgements}

The authors would like to thank owusu samuel, eshun franklina, and hamidu rawuuf kontangu for their role in data collection. We also would like to thank the management and staff of Tamale Teaching Hospital donor clinic and all the participants for their cooperation.

\section{Funding}

Not applicable.

\section{Availability of data and materials}

The datasets used and/or analysed during the current study are available from the corresponding author on reasonable request.

\section{Authors' contributions}

SM conceived and designed the study, supervised data collection, performed analysis, and interpretation of data and drafted the manuscript. HBE supervised the design, analysis, and interpretation of data and reviewed the draft of the manuscript. Both authors read and approved the final draft of the manuscript.

\section{Ethics approval and consent to participate}

The study protocol was reviewed and approved by the institutional research and development committee of Tamale Teaching Hospital. Participation was voluntary and participants indicated consent by signing a consent form after adequate information was provided on the purpose of the study, its possible benefits, and their role in the study. Additionally, participants were informed they could withdraw from the study at any time. Sufficient time was allowed for participants to decide whether to participate in the study. We ensured confidentiality of the study data and maintained the anonymity of the study participants.

\section{Consent for publication}

Not applicable.

\section{Competing interests}

The authors declare that they have no competing interests.

\section{Publisher's Note}

Springer Nature remains neutral with regard to jurisdictional claims in published maps and institutional affiliations.

\section{Author details}

'Department of Nursing, College of Nursing and Midwifery, Post office box 10, Nalerigu, Ghana. 'Educational Innovations in Science and Technology, Kwame Nkrumah University of Science and Technology, Kumasi, Ashanti Region, Ghana. 
Received: 25 May 2018 Accepted: 28 November 2018

Published online: 20 December 2018

\section{References}

1. $\mathrm{WHO}$ and International Federation of Red Cross. Towards $100 \%$ Voluntary Blood Donation: A global framework for Action [Internet]. Geneva; 2010. Available from: http://www.who.int/iris/handle/10665/44359.

2. Tapko JB, Toure B, Sambo LG. Status Of Blood Safety In The Who African Region: Report of the 2010 Survey [Internet]. Brazzaville; 2014. Available from: http://who.insomnation.com/sites/default/files/pdf/status-of-bloodsafety-in-the-who-african-region.pdf

3. WHO. Blood safety and availability [Internet]. 2017 [cited 2018 Jan 28]. Available from: https://www.who.int/en/news-room/fact-sheets/detail/ blood-safety-and-availability.

4. Ministry of Health. National Blood Policy for the Health Sector [Internet] Ghana; 2006. Available from: http://www.who.int/bloodsafety/transfusion_ services/GhanaNationalBloodPolicy2006.pdf.

5. WHO. Campaign Essentials: World Blood Donor Day 2014 [Internet]. Geneva; 2014. Available from: http://www.who.int/campaigns/world-blood-donorday/2014/en/

6. Ogbu O, Uneke C. Hepatitis B virus and Blood transfusion safety in subSaharan Africa. Internet J Infect Dis. 2008;7(2):1-7 Available from: https:// print.ispub.com/api/0/ispub-article/4114

7. Ministry of Health. National Blood Transfusion Service requires 250,000 units of blood annually. 2010.

8. Ansah JK. About 160,624 units of blood collected nationwide in 2016; 2016.

9. WHO. CAMPAIGN ESSENTIALS: World Blood Donor Day 2015 [Internet]. Geneva; 2015. Available from: http://www.who.int/campaigns/world-blooddonor-day/2015/campaign-essentials/en/

10. Allain J-P, Sarkodie F, Asenso-Mensah K, Owusu-Ofori S. Relative safety of first-time volunteer and replacement donors in West Africa. Transfusion. 2010;50:340-3

11. Asamoah-akuoko L, Hassall OW, Bates I. Blood donors ' perceptions, motivators and deterrents in sub-Saharan Africa - a scoping review of evidence. $\mathrm{Br} J$ Haematol. 2017:177:864-77.

12. Koster J, Hassall OW. Attitudes towards blood donation and transfusion in Bamenda, Republic of Cameroon. Transfus Med. 2011:21:301-7.

13. Manikandan S, Srikumar R, Ruvanthika PN. A Study on Knowledge, attitude and practice on Blood donation among health professional students in. Int J Sci Res Publ. 2013;3(3):3-6.

14. Suemnig A, Konerding U, Hron G, Lubenow N, Alpen U, Hoffmann W, et al. Motivational factors for blood donation in first-time donors and repeat donors: a cross-sectional study in West Pomerania. Transfus Med. 2017 27(6):413-20.

15. Shaz BH, Demmons DG, Crittenden CP, Carnevale CV, Burnett M, Easley K, et al. Motivators and Barriers to Blood Donation in African American College Students. Transfus Apher Sci. 2010;41(3):191-7.

16. Alfouzan N. Knowledge, Attitudes, and Motivations towards Blood Donation among King Abdulaziz Medical City Population. Int J Fam Med. 2014;2014:539670 Available from: https://doi.org/10.1155/2014/539670.

17. Thakur A, Singh $H$, Bishwas C. Knowledge and practices of blood donation among the undergraduate students of district Una, Himachal Pradesh, India. Glob J Med Publ Heal. 2015;4(6):1-7.

18. Nwogoh B, Aigberadion U, Nwannadi Al. Knowledge, attitude, and practice of voluntary Blood donation among healthcare Workers at the University of Benin teaching hospital, Benin City, Nigeria. J Blood Transfus. 2013:2013:797830.

19. Wiersum-osselton JC, Der Kreek TM, Brand A, Veldhuizen I, Van Der Bom JG, De Kort W. Risk factors for complications in donors at first and repeat whole blood donation: a cohort study with assessment of the impact on donor return. Blood Transfus. 2014;12:28-36.

20. Allain J. Moving on from voluntary non-remunerated donors: who is the best blood donor? Br J Haematol. 2011;154:763-9.

21. Duboz P, Macia E. Blood donors and blood collection. Transfusion. 2010;50: 2713-20.

22. Shaz $B H$, Demmons DG, Hillyer $\mathrm{KL}$, Jones RE, Hillyer CD. Racial differences in motivators and barriers to Blood donation among Blood donors Beth. Arch Pathol Lab Med. 2009;133:2-4.

23. Mauka WI, Mahande MJ, Msuya SE, Philemon RN. Factors associated with repeat Blood donation at the northern zone Blood transfusion Centre in Tanzania. J Blood Transfus. 2015;2015:717653.
24. Finck R, Ziman A, Hoffman M, Phan-tang M, Yuan S. Motivating factors and potential deterrents to Blood donation in high school aged Blood donors. J Blood Transfus. 2016;2016:8624230.

25. Sachdev S, Mishra SK, Marwaha N, Avasthi A. Study of knowledge and attitude among college-going students toward voluntary blood donation from north India. J Blood Med. 2016;(7):19-26 Available from: https://www. dovepress.com/study-of-knowledge-and-attitude-among-college-goingstudents-toward-vo-peer-reviewed-article-JBM.

26. Yuan S, Hoffman M, Lu Q, Goldfinger D, Ziman A. Motivating factors and deterrents for blood donation among donors at a university campus-based collection center. Transfusion. 2011;51:2438-44.

27. Schlumpf KS, Glynn SA, Schreiber GB, Wright DJ, Steele WR, Tu Y, et al. Factors influencing donor return. Transfusion. 2008;48:264-72.

28. Jemberu YA, Esmael A, Ahmed KY. Knowledge, attitude and practice towards blood donation and associated factors among adults in Debre Markos town, Northwest Ethiopia. BMC Hematol. 2016;16(1):1-8 Available from: https://doi.org/10.1186/s12878-016-0062-8
Ready to submit your research? Choose BMC and benefit from:

- fast, convenient online submission

- thorough peer review by experienced researchers in your field

- rapid publication on acceptance

- support for research data, including large and complex data types

- gold Open Access which fosters wider collaboration and increased citations

- maximum visibility for your research: over $100 \mathrm{M}$ website views per year

At BMC, research is always in progress.

Learn more biomedcentral.com/submissions 